\title{
Management of dyslipidemia in HIV-infected patients
}

\author{
Carlos D Malvestutto ${ }^{\dagger}$ and Judith A Aberg ${ }^{1}$ \\ ${ }^{1}$ Division of Infectious Diseases \& Immunology, Bellevue Hospital Center, New York University \\ School of Medicine, NY, USA
}

\begin{abstract}
Antiretroviral therapy has dramatically increased survival for HIV-infected individuals. As this population lives longer, coronary heart disease has become an important comorbid condition. Dyslipidemia in HIV-infected individuals is a complex condition, with multiple contributing factors including the HIV virus itself, individual genetic characteristics and antiretroviral therapyinduced metabolic changes. Effective management of dyslipidemia in this population is essential to reduce cardiovascular risk but presents multiple challenges due to interactions between antiretroviral therapy agents and lipid-lowering medications.
\end{abstract}

\section{Keywords}

drug interactions; fibrates; fish oil; guidelines; HIV-associated dyslipidemia;

hypertriglyceridemia; niacin; statins

\begin{abstract}
The risk of coronary heart disease (CHD) is increased among persons infected with HIV compared with the uninfected population [1,2]. For example, in a cohort study comparing 5430 HIV-infected men with HIV-uninfected men enrolled in the healthcare organization, Kaiser Permanente, in northern California (CA, USA), age-adjusted CHD and myocardial infarction rates were significantly higher for HIV-infected men compared with HIVuninfected men (6.0 vs 2.9 events $/ 1000$ person years, $\mathrm{p}<0.0001$ for CHD and 3.6 vs 2.2 events/1000 person years, $p<0.002$ for myocardial infarction) [3]. Similarly, an increased risk of CHD has been demonstrated among HIV-infected cohorts observed at two large hospitals in Boston [4] and in a national cohort in Denmark [5]. The increased CHD risk observed among HIV-infected persons is due mostly (although not exclusively) to traditional risk factors such as smoking, diabetes and dyslipidemia [6]. However, the effects of various antiretroviral drugs [1] as well as chronic inflammation [7] and immune activation [8] due to the HIV virus itself are important contributors to the excess CHD risk observed in this population. Carotid intima-media thickness (CIMT) is a well-established marker of atherosclerotic progression and an increasing CIMT has been demonstrated to correlate with increased risk of myocardial infarction and stroke in the general population $[9,10]$. Although
\end{abstract}

\footnotetext{
${ }^{\dagger}$ Author for correspondence: Division of Infectious Diseases, New York University Langone Medical Center, NY, USA, Tel.: +1 917 263 6565, Fax: +1 212263 8264, carlos.malvestutto@ nyumc.org.

For reprint orders, please contact: reprints@futuremedicine.com

Financial \& competing interests disclosure

This research was supported in part by the ACTG funded by the National Institute of Allergy and Infectious Diseases Grant AI069532. JA Aberg has served as a consultant for Kowa Research Institute, Merck, Tibotec and Viiv in the past 12 months. In addition, both JA Aberg and CD Malvestutto serve or have served in the past 12 months as investigators for multicenter trials sponsored by Gilead, GlaxoSmithKline, Kowa, Pfizer and Tibotec. The authors have no other relevant affiliations or financial involvement with any organization or entity with a financial interest in or financial conflict with the subject matter or materials discussed in the manuscript apart from those disclosed.

No writing assistance was utilized in the production of this manuscript.
} 
a similar correlation between CIMT and CHD events in HIV-infected individuals still remains to be demonstrated, several studies demonstrate an increased and more rapid progression of CIMT among HIV-infected individuals compared with HIV-uninfected persons. For example, data from the Fat Redistribution and Metabolic Change in HIV Infection (FRAM) cross-sectional study demonstrated that HIV infection was associated with increased CIMT independently of traditional risk factors and to a similar degree as smoking and male gender. In this study, $94 \%$ of the HIV-infected participants were on antiretroviral therapy (ART) [11]. A meta-analysis that included six prospective cohort studies, three case-control studies and four cross-sectional studies confirmed a statistically significant increase in CIMT for HIV patients compared with HIV-uninfected persons [12]. In a another study that assessed the degree of atherosclerosis through computed tomography coronary angiography, significant subclinical CHD was demonstrated in asymptomatic young HIV-infected men without prior history of cardiovascular disease. The prevalence and degree of coronary disease in these HIV-infected men was significantly greater than in HIV-seronegative men with similar demographics, Framingham Risk Scores and traditional risk factors (family history, BMI, smoking and total cholesterol [TC]), and LDL-C [13].

Data from Kaiser Permanente in California and the HIV Outpatient Study suggest that although MI rates among HIV patients remain elevated compared with the HIV-uninfected population, these rates have been decreasing gradually since the late 1990s. This gradual reduction between 1996 and 2008 correlates with increased use of lipid-lowering and antihypertensive medications, the availability of more lipid-friendly ART regimens, and more effective management of cardiovascular risk factors (as supported by stable Framingham Risk Scores in an aging population) in the HIV-infected population during the same period [14,15].

This article discusses important aspects of dyslipidemia in HIV-infected patients, including its clinical presentation, pathophysiology and management considerations, taking into account interactions between lipid-lowering medications and antiretroviral medications.

\section{Dyslipidemia in HIV infection}

Several large prospective studies such as the Framingham Heart Study [16], the Multiple Risk Factor Intervention Trial [17] and the Lipid Research Clinics [18] studies have demonstrated a direct association between levels of LDL-C and risk of CHD in the general population. Strong evidence also correlates decreased HDL-C levels with increased CHD incidence and mortality [19]. Epidemiological studies have also reported an association between triglyceride (TG) levels and risk of CHD [18,20]. After adjusting for baseline risk factors a report of two case-control studies showed TG to be an independent risk factor for CHD with an odds ratio for CHD of 1.76 (95\% CI: 1.39-2.21) in the Reykjavik study and 1.57 (95\% CI: 1.10-2.24) in the EPIC-Norfolk study. A similar independent association was observed in a meta-analysis of 29 prospective studies reported in the same publication (odds ratio: 1.72, 95\% CI: 1.56-1.90) [21]. An analysis from the D:A:D study also demonstrated that TG was an independent risk factor for CHD among HIV-infected patients [22].

The natural history of HIV infection is associated with characteristic changes in lipid levels. As HIV disease progresses, there is an initial decrease in HDL-C followed by a decrease in LDL-C. In more advanced stages, there is an increase in TGs and in VLDL-C [2]. These declines in TC, LDL-C and HDL-C observed after HIV sero-conversion are consistent with a chronic inflammatory state. There is evidence of an abnormal HDL-C metabolism in HIVinfected patients compared with uninfected persons: Rose et al. found increased activity and mass of cholesterol ester transfer protein in HIV-infected patients. As this pathway mediates exchange of VLDL-TG and HDL-C ester, it may explain the low HDL-C levels often seen 
in HIV-infected persons [23]. Furthermore, HIV itself impairs the ATP-binding cassette transporter A1-mediated cholesterol efflux from infected macrophages, resulting in decreased HDL-C production [24]. After initiation of ART, lipid levels return to baseline levels and then soon increase above pre-seroconversion levels, except for HDL-C which remains persistently low [25-27]. These changes are consistent with a general 'return to health' state as well as direct antiretroviral effects. The magnitude of these lipid changes after seroconversion and even after initiation of ART varies widely among patients and is subject to host characteristics such as gender and ethnicity/race and genomic traits such as mitochondrial haplotypes [28].

Overall, the loss of protection against atherosclerosis due to reduced HDL-C likely outweighs the potential benefit of reduced LDL-C and TC in untreated HIV infection [29]. For example, in the Strategies for Management of Anti-Retroviral Therapy (SMART) study, which randomized HIV-infected patients to continuous ART or intermittent ART, those who received ART intermittently had reduced TC, LDL-C, TG and HDL-C levels at 1 year, while those randomized to receive continuous ART had increases in lipids including HDL-C during the same period. However, the greater proportional decrease in HDL-C than TC among those on intermittent ART resulted in an increased TC:HDL-C ratio. On the other hand, for those on continued ART the TC:HDL-C ratio declined [30]. The study investigators suggest that this difference in TC:HDL-C ratio may contribute to the increased risk of cardiovascular events in patients on intermittent ART compared with those on continuous ART. It should be noted, however, that although various studies have reported an inverse epidemiologic association between HDL-C and risk of CHD both in the general population [31,32] and in HIV-infected patients [1], there is currently inconclusive evidence that therapeutically increasing circulating HDL-C actually reduces the risk of cardiovascular events [33].

\section{Effect of ART on lipids}

Different ART classes and even individual agents within each drug class can have disparate effects on lipid levels. Patient characteristics such as gender and race/ethnicity [34] and drug metabolism polymorphisms play an important role in determining variations in lipids between individuals taking the same antiretroviral drug [35-37]. Except for unboosted atazanavir, protease inhibitors (PIs) generally increase LDL-C and TG [38] most notably when paired with ritonavir as a pharmacological booster [39]. Generally, boosted PIs have similar lipid profiles with a few exceptions: tipranavir (which must be boosted with a higher dose of ritonavir than other PIs) causes marked increases in TC and TG. On the other hand, atazanavir and darunavir with a ritonavir booster cause more modest increases in lipids compared with other PIs [40-42].

In contrast to PIs, non-nucleoside reverse transcriptase inhibitors (NNRTIs) increase lipids only modestly if at all. Efavirenz added to a double or triple nucleoside reverse transcriptase inhibitor (NRTI) backbone results in small increases in all lipids including HDL-C compared with a triple NRTI only regimen at 96 weeks [43]. A head-to-head comparison of efavirenz with nevirapine in initial regimens demonstrated a more favorable lipid profile for nevirapine with a larger increase in HDL-C (33.6 vs $24.7 \%$; $p$ < 0.007$)$ and lower increase in TG (20.1 vs 49.0\%; p < 0.001) at 48 weeks [44]. Adding etravirine to a regimen that contains darunavir/ritonavir and NRTIs does not result in excess increase in lipid parameters [45].

Mitochondrial toxicity [46], although rarely observed with newer antiretrovirals, has been associated with the NRTI drug class, and thymidine analogs (zidovudine and stavudine), in particular, are believed to disrupt metabolic pathways through changes in sterol-regulatory binding proteins leading to insulin resistance and dyslipidemia [47]. 
The D:A:D observational cohort study found that the NRTI abacavir increased the risk of myocardial infarction (relative risk $=1.90$ ) [48]. This reported association remains controversial and several studies including a recent analysis from the AIDS Clinical Trial Group (ACTG) ALLRT cohort [49] and a meta-analysis conducted by the US FDA [50] failed to confirm this finding. Although the pathogenesis of the purported temporary association between abacavir and CHD is not yet understood, platelet hyper-reactivity [51,52], endothelial dysfunction [53,54] and cardiotoxicity via vascular inflammation [55] have been proposed as possible explanations rather than lipid perturbations.

Apart from stavudine, which causes significant increases in lipids, other NRTIs generally produce smaller lipid increases compared with PIs or NNRTIs. In a meta-analysis of 15 clinical trials of first-line ART by Hill et al., fosamprenavir/ritonavir, lopinavir/ritonavir or the NNRTI efavirenz in combination with NRTIs other than tenofovir were associated with the greatest increases in TC at 48 weeks. Tenofovir-containing regimens resulted in smaller increases in TC [56]. Furthermore, a small $(n=17)$ randomized, placebo-controlled study by Tungsiripat et al. suggests that tenofovir may have independent lipid-lowering properties when combined with a stable, virologically suppressive ART regimen in HIV-infected patients with dyslipidemia. Non-HDL-C, LDL-C and TC were significantly lower at 12 weeks on tenofovir compared with placebo [57]. An intensive metabolic study conducted by Randell and colleagues also noted significant decreases in TC and LDL-C among HIV seronegative individuals while on tenofovir compared with placebo [58].

Thus far, fusion inhibitors (e.g., enfuvirtide), CCR5 receptor inhibitors (e.g., maraviroc) and integrase inhibitors (e.g., raltegravir) have not been associated with significant lipid changes [59-63]. Elvitegravir, an investigational integrase inhibitor requires pharmacologic boosting and it is not yet known what effect it may have on lipids.

\section{Genetic factors}

Genetic factors play important roles and account for a significant proportion of the variability in lipids among HIV-infected patients both prior to and after starting ART. Rotger et al. analyzed the contribution of 42 single nucleotide polymorphisms and key nongenetic factors such as ART and HIV disease characteristics to dyslipidemia in 745 Swiss HIV cohort participants. Single nucleotide polymorphisms accounted for $8 \%$ of the variability in non-HDL-C, $6 \%$ in HDL-C and 7\% in TG. ART contributed slightly less to the variability in these lipid parameters. Compared to an individual with the least dyslipidemic genetic profile and ART regimen, a person with the most dyslipidemic genetic profile and ART regimen had a three- to five-fold increased risk of sustained dyslipidemia [64].

\section{Lipid management guidelines}

The HIV Medical Association of the Infectious Disease Society of America (IDSA) and ACTG guidelines [65] support managing dyslipdemia in HIV-infected patients as in the general population according to the National Cholesterol Education Program (NCEP) Adult Treatment Panel III guidelines [201].

Although the Framingham Risk Score has not been formally validated in patients with HIV, observed myocardial infarction (MI) rates in the D:A:D cohort correlated with rates predicted by the Framingham equation [66]. Thus, the Framingham Risk Score offers a less than accurate but acceptable approximation of risk in HIV patients currently endorsed by both the IDSA and European AIDS Clinical Society (EACS) guidelines at this time. A CHD risk prevention model for HIV-infected patients has been developed, but has not yet been validated [67]. According to IDSA guidelines, HIV-infected patients with two or more traditional CHD risk factors should have their 10-year CHD risk calculated using the 
Framingham Risk Score equation. EACS guidelines recommend assessment of the 10-year CHD risk for all patients [68]. Lipid targets should be set for each individual patient. Lifestyle modification interventions including diet, exercise and smoking cessation should be advised to all patients. If the individual is unable to reach lipid targets with lifestyle modification interventions, lipid-lowering drugs should be started or alteration of ART should be considered. There are important differences between EACS and IDSA guidelines. EACS recommends initiating statins and/or cholesterol uptake inhibitor if TC $>190 \mathrm{mg} / \mathrm{dl}$ and/or LDL-C $>115 \mathrm{mg} / \mathrm{dl}$ to achieve optimal levels of $<155$ and $<80 \mathrm{mg} / \mathrm{dl}$ for TC and LDL-C, respectively. EACS guidelines do not recommend treatment of moderate TG levels due to unclear evidence of increased CHD risk among persons with HIV infection. IDSA guidelines recommend initiation of a statin first for elevated non-HDL-C when TG levels are between 200 and $500 \mathrm{mg} / \mathrm{dl}$. If the TG level is higher than $500 \mathrm{mg} / \mathrm{dl}$, initial treatment with a fibrate is recommended consistent with the recommendations of the American Heart Association (AHA) and NCEP guidelines for all populations. Special considerations for this patient population include pre-existing dyslipidemia prior to initiation of ART, possible effects of ART drugs on lipids and possible drug interactions between ART agents and lipidlowering medications.

\section{Drug interactions between ART \& lipid-lowering drugs}

One of the main challenges in treating dyslipidemia in HIV patients is selecting lipidlowering agents that will work effectively and safely to reach lipid goals while taking into account drug-drug interactions with ART agents (Table 1). The PIs, NNRTIs and some statins are metabolized by the cytochrome P450 isoenzyme CYP3A4. For example, the simvastatin area under the curve (AUC) increases 32-fold when co-administered with the PI combination of saquinavir/ritonavir due to inhibition of CYP3A4 by the PI [69]. Therefore, simvastatin is contraindicated for patients taking PIs to avoid placing patients at risk of rhabdomyolysis [70]. A similar interaction with PIs would be expected with lovastatin, which should also be avoided. Atorvastatin increases moderately approximately twofold in the presence of PIs [69]; therefore, it can be given but at lower doses than in the general population and titrated as tolerated. Pravastatin is eliminated through pathways other than CYP3A4 and can be used safely with most PIs. However, it may be less effective due to induction of enzymes that metabolize pravastatin, thus lowering its concentration in the presence of PIs [69,71]. In the presence of darunavir, on the other hand, pravastatin levels may increase up to fivefold $[69,71]$ depending on polymorphisms within the SLCO1B1 drug transporter gene thereby making it difficult to predict whether a significant interaction will occur or not [72]. Therefore, the darunavir package insert recommends that the lowest possible dose of pravastatin, atorvastatin or rosuvastatin be used in patients taking darunavir [73].

Like pravastatin, the recently FDA-approved pitavastatin (Livalo ${ }^{\circledR}$ ) is only minimally metabolized through CYP3A4. A pharmacokinetic study to evaluate drug-drug interactions between atazanavir and pitavastatin demonstrated no clinically significant changes in drug concentrations for either drug. Therefore, they can be co-administered safely without dose adjustment [74]. The package insert for pitavastatin warns against using this statin with lopinavir/ritonavir due to lack of data regarding any possible interactions [74]. No data are available at this time on co-administration with NNRTIs.

Certain PIs markedly increase rosuvastatin blood concentrations through a non-CYP3A4 mechanism. Lopinavir/ritonavir increased rosuvastatin concentration almost fivefold [75] while ritonavir-boosted fosamprenavir increased it sixfold [76]. Ritonavir-boosted atazanavir did not appear to increase rosuvastatin levels [76]. 
Non-nucleoside reverse transcriptase inhibitors also interact with statins. Efavirenz is a mixed inducer/inhibitor of CYP3A4. Efavirenz decreases simvastatin AUC by $58 \%$, atorvastatin AUC by $43 \%$, and (unexpectedly) also pravastatin AUC by $40 \%$ [77]. Thus, higher doses of these statins may be required for use with efavirenz. Etravirine may increase the AUC of fluvastatin [78]. The integrase inhibitor raltegravir avoids P450 isoenzyme substrate processing and is eliminated mainly by UGT1A1 glucuronidation and would not be expected to interact significantly with statins. A recent published study confirms a lack of significant interaction between pravastatin and raltegravir [79]. Another integrase inhibitor currently in development, elvitegravir, is a CYP3A inducer but no interactions with statins have been reported thus far. The CCR5 receptor inhibitor, maraviroc, is a CYP3A substrate and may have important interactions with statins. Caution is recommended if lipid-lowering medications are prescribed with antiretrovirals and patients should be monitored for any potential toxicities [80].

\section{Studies of lipid-lowering strategies in HIV-infected patients}

Lipid-lowering drugs in HIV-infected patients produce similar or somewhat smaller lipid reductions compared with those achieved in the general population. For example, data from Kaiser Permanente demonstrated reductions in LDL-C of approximately $19 \%$ for both HIVinfected and HIV-uninfected patients with any lipid-lowering therapy and slightly lower at 25.6\% for HIV-infected patients versus $28.3 \%$ for HIV-uninfected patients $(\mathrm{p}=0.01)$ when statins were used. HIV-infected patients with elevated TGs initiating gemfibrozil had markedly smaller reductions in triglyceride levels than patients without HIV infection (44.2 vs 59.3\%; $\mathrm{p}$ < 0.001) [81]. However, other lipid-lowering studies have demonstrated that the percentage reduction in lipids was similar to that expected in the general population $[82,83]$. One must be cautious when interpreting lipid-lowering studies among those with HIV and other inflammatory conditions, as the population may have more mixed dyslipidemias and while the actual percentage of subjects may not reach the targeted goal, the percentage reductions obtained are within the expected response. For instance, a statin given to someone with high TGs initially may have suboptimal response, but a statin is not indicated for treatment of hypertriglyceridemia. And if that same person is subsequently given a fibrate, the LDL may actually increase as TG decrease leading to misinterpretation of the efficacy of the statin.

There is now extensive clinical trial experience with various lipid-lowering therapies, particularly statins in HIV-infected patients. The most frequently used statin drug in interventional trials was pravastatin due to its favorable safety profile with PIs and NNRTIs. Some interventional clinical trials of similar lipid-lowering therapies have disparate results. This may be due to the inclusion patients with various different types of dyslipidemias, which could have affected outcomes.

\section{Dietary control versus statins}

An open-label, randomized trial comparing dietary advice alone or dietary advice plus pravastatin was conducted by Moyle et al. in 31 male patients with TC greater than $252 \mathrm{mg} /$ dl. Baseline TC levels were $286 \mathrm{mg} / \mathrm{dl}$ in the dietary advice arm and $290 \mathrm{mg} / \mathrm{dl}$ in the pravastatin arm. At week 24 , the TC decreased by $46 \mathrm{mg} / \mathrm{dl}$ in the pravastatin arm but only by $12 \mathrm{mg} / \mathrm{dl}$ in the dietary advice arm but the different was only borderline statistically significant $(\mathrm{p}=0.051)$. There was no significant difference in TG [84].

\section{Fibrates versus statins}

An open-label, randomized trial of bezafibrate, gemfibrozil, fenofibrate, pravastatin and fluvastatin for treatment of PI-associated dyslipidemia was conducted by Calza et al. [85]. 
Fibrate use $(n=69)$ reduced TG by $41 \%$ and LDL-C by $23 \%$. Statin use $(n=37)$ reduced TG by $35 \%$ and LDL-C by $26 \%$. HDL-C was increased by $20 \%$ in those who used fibrates and by $24 \%$ in those who used statins (differences were not statistically significant).

The ACTG A5087 study was a randomized, open-label, trial comparing the use of pravastatin $40 \mathrm{mg} /$ day to fenofibrate $200 \mathrm{mg} /$ day for the treatment of mixed dyslipidemia in 174 HIV-infected patients [82]. Patients who failed single-agent therapy at 12 weeks were given both agents until study completion at week 48 . For the 87 patients on fenofibrate monotherapy, 9, 66 and 48\% achieved LDL-C, HDL-C and TG NCEP targets at week 12, respectively, while of the 83 patients on pravastatin monotherapy 36, 49 and $18 \%$ achieved NCEP targets for LDL-C, HDL-C and TG, respectively, by week 12 . Those patients who completed combination therapy with fenofibrate and pravastatin attained additional improvements in lipid parameters [82]. Markers of inflammation and platelet activation including plaminogenactiator inhibitor (PAI)-1, P-selectin, and high-sensitivity C-reactive protein (hs-CRP) were not appreciably changed [86].

\section{Statin studies}

Although there are few head-to-head studies comparing different statin agents in HIVinfected patients, it appears that rosuvastatin may be superior than pravastatin and low-dose atorvastatin in reducing TC and LDL-C in patients taking PI-based ART. The Agence Nationale de Recherche sur le SIDA conducted ANRS 126, a randomized, open-label trial comparing pravastatin $40 \mathrm{mg} /$ day with rosuvastatin $10 \mathrm{mg} /$ day. A total of 42 patients taking PIs were randomized to each arm and had a baseline median TC of $292 \mathrm{mg} / \mathrm{dl}$, LDL-C of $192 \mathrm{mg} / \mathrm{dl}$, HDL-C of $50 \mathrm{mg} / \mathrm{dl}$ and TG of $204 \mathrm{mg} / \mathrm{dl}$. After 45 days, rosuvastatin reduced LDL-C by $37 \%(-1.69+0.87 \mathrm{mmol} / \mathrm{l})$ versus $19 \%(-0.92+0.79 \mathrm{mmol} / \mathrm{l})$ for pravastatin (p $<0.001)$. TG was reduced by $19 \%(-0.67+1.02 \mathrm{mmol} / \mathrm{l})$ versus $7 \%(-0.20+0.95 \mathrm{mmol} / \mathrm{l})$ for rosuvastatin and pravastatin, respectively $(\mathrm{p}=0.035)$. HDL-C levels did not differ between the study arms [87]. Another study by Calza et al. randomized 94 HIV-infected patients with hyper-cholesterolemia to rosuvastatin $10 \mathrm{mg} /$ day or pravastatin $20 \mathrm{mg} /$ day or atorvastatin $10 \mathrm{mg} /$ day. Mean decrease in TC concentration was significantly greater with rosuvastatin $(25.2 \%)$ than with pravastatin $(17.6 \% ; \mathrm{p}=0.01)$ and atorvastatin $(19.8 \% ; \mathrm{p}=$ $0.03)$ at 12 months [88].

Beyond their lipid-lowering effects, statins have well-established anti-inflammatory effects in the general population. In the JUPITER study, reduction in the inflammatory marker hsCRP levels with the use of rosuvastatin has been demonstrated to result in decreased CHD and all-cause mortality independently of reductions in LDL-C in HIV-uninfected patients with normal baseline LDL-C and elevated hs-CRP > $2 \mathrm{mg} / \mathrm{dl}$ [89]. However, appropriate inflammatory markers have yet to be identified among persons with HIV infection that can serve as surrogate markers of other disease activity such as CHD. It may well be that the statins may not exert significant anti-inflammatory effects given the overall inflammatory state of HIV itself; nevertheless, this should not negate the benefits that statins may have via their lipid-lowering and unknown cardioprotective properties. Even in the JUPITER study, the hs-CRP and LDL reduction was only slightly correlated with outcomes suggesting that there are other properties contributing to this risk reduction [89].

\section{Ezetimibe}

Ezetimibe reduces dietary and biliary cholesterol absorption at the intestinal brush border, resulting in a reduction of hepatic cholesterol stores and an increase in clearance of cholesterol from the blood. It has been demonstrated to be effective in reducing LDL-C levels in HIV-infected patients, particularly among those unable to reach LDL-C goals with statin treatment alone. The disappointing results of the general population study Ezetimibe 
and Simvastatin in Hypercholesterolemia Enhances Atherosclerosis Regression

(ENHANCE), which failed to demonstrate an advantage of the statin/ezetimibe combination on the primary end point of reduction in mean CIMT (although it showed a robust additive reduction in LDL-C of approximately $50 \mathrm{mg} / \mathrm{dl}$ ) should not preclude its use in HIV-infected patients [90]. The combined use of ezetimibe with statins in HIV-infected patients is appealing for patients who do not achieve lipid goals while receiving a statin alone or who are unable to tolerate high statin doses. Unlike statins, ezetimibe does not interact with cytochome CYP3A4 and will not increase the risk of toxicity or pharmacokinetic interactions with ART [91].

Bennett et al. conducted a retrospective analysis of lipid levels for $33 \mathrm{HIV}$-infected patients prescribed ezetimibe $10 \mathrm{mg} /$ day [92]. Mean TC was reduced by $21 \%$ from 6.95 to 5.51 $\mathrm{mmol} / \mathrm{l}(\mathrm{p}<0.001)$, while LDL-C was reduced by $35 \%$ from 4.05 to $2.63 \mathrm{mmol} / \mathrm{l}(\mathrm{p}<$ 0.001 ), TG was reduced by $34 \%$ from 6.22 to $3.85 \mathrm{mmol} / \mathrm{l}$ ( $\mathrm{p}<0.001$ ). Mean HDL-C increased by $8 \%$ from 1.07 to $1.16 \mathrm{mmol} / \mathrm{l}(\mathrm{p}=0.038)$.

A small, double-blind, placebo-controlled, crossover design study compared ezetimibe 10 $\mathrm{mg} / \mathrm{dl}$ versus placebo in $48 \mathrm{HIV}$-infected patients. A small change was observed, $35 \%$ of participants reached at least $17 \%$ reduction in LDL-C but there were no significant changes in TG or HDL-C [83].

Negredo et al. conducted an open-label prospective study where ezetimibe $10 \mathrm{mg} / \mathrm{day}$ was administered to $19 \mathrm{HIV}$-infected patients who were already taking pravastatin $20 \mathrm{mg} / \mathrm{day}$ and had LDL-C levels higher than $130 \mathrm{mg} / \mathrm{dl}$. At week 24, 61.5\% of patients had reached LDL-C less than $130 \mathrm{mg} / \mathrm{dl}$. No differences were observed in lopinavir and nevirapine drug levels measured before and after 12 weeks on ezetimibe [91].

The ACTG A5209 study was a multicenter double-blind, randomized, placebo-controlled, crossover study with similar inclusion criteria and therapeutic intervention as the study by Negredo et al. A total of $44 \mathrm{HIV}$-infected adults on stable ART with LDL-C > $130 \mathrm{mg} / \mathrm{dl}$ and on stable statin therapy were randomized to receive ezetimibe $10 \mathrm{mg}$ daily or placebo for 12 weeks followed by 4 weeks of washout and then 12 weeks with the alternative study assignment. Median percentage decrease in LDL-C was $20.8 \%$ with ezetimibe and $0.7 \%$ with placebo. Median difference in LDL-C between ezetimibe and placebo was $32 \mathrm{mg} / \mathrm{dl}$ (p $<0.0001)$. Significant within-participants changes were noted favoring ezetimibe with reductions in TC, non-HDL-C and ApoB of 18.6, 23.2 and 8.7\%, respectively. No significant changes were noted in HDL-C or TG [93].

\section{Bile acid sequestrants}

There are no published data on the use of bile acid sequestrants to manage dyslipidemia in HIV-infected patients. This is likely due to the concern that these drugs could decrease the absorption of ART medications. Furthermore, bile acid binders are known to increase TG levels, potentially exacerbating a common lipid abnormality in the HIV-infected population [94].

\section{Targeting elevated TGs in HIV-infected patients}

Elevated TG is the most common lipid abnormality in HIV-infected patients. Although statins have some effect on TG, first-line therapy for TG involves fibrate therapy followed by fish oil or niacin [65]. Some fibrates, such as gemfibrozil, are metabolized in the liver via uridine 5'-diphosphate-glucuronosyl transferase enzyme, which is induced by most PIs. PI induction of this enzyme would likely cause a reduced concentration of gemfibrozil in blood, which could explain its reported low efficacy in HIV-infected patients $[81,95]$. 


\section{Gemfibrozil versus diet}

A 16-week, randomized, double-blind, placebo-controlled study comparing a low saturated fat diet versus a low saturated fat diet with gemfibrozil $600 \mathrm{mg}$ twice daily in $37 \mathrm{HIV}$ infected men taking PIs with fasting TG $>266 \mathrm{mg} / \mathrm{dl}$ was conducted by Miller et al. Median fasting TG at baseline was $496 \mathrm{mg} / \mathrm{dl}$. Mean changes in TG from week 4 to 16 were -108 $\mathrm{mg} / \mathrm{dl}$ for the gemfibrozil group and $+31 \mathrm{mg} / \mathrm{dl}$ for the placebo group. However, the difference between the groups was not statistically significant and the investigators concluded that gemfibrozil was safe but provided only modest efficacy in HIV-infected patients taking PIs [94].

\section{Fenofibrate}

Due to the lack of drug-drug interaction between fenofibrate and ART drugs, fenofibrate is now the most commonly prescribed fibrate for HIV-infected patients with elevated TG [95]. Several case reports by Thomas et al. [96] and de Luis et al. demonstrated initial TGlowering activity of fenofibrate in HIV-infected patients [97]. Subsequently, Calza et al. [85] and Caramelli et al. [98] demonstrated further efficacy of fenofibrate in larger case series. In a prospective study by Palacios et al., 20 patients on ART with baseline fasting TG levels $>400 \mathrm{mg} / \mathrm{dl}$ despite adherence to fitness and dietary measures were given micronized fenofibrate $200 \mathrm{mg} /$ day and the TG level decreased from a mean of $812 \mathrm{mg} / \mathrm{dl}$ to $377 \mathrm{mg} / \mathrm{dl}$ (54\% reduction; $\mathrm{p}=0.0001$ ) after 24 weeks [99]. ACTG 5087 also demonstrated excellent improvement in TG at 12 weeks for patients on fenofibrate $200 \mathrm{mg}$ /day compared with those on the pravastatin $40 \mathrm{mg} / \mathrm{day}$ arm, $35 \%(-118 \mathrm{mg} / \mathrm{dl})$ versus $13 \%(-27 \mathrm{mg} / \mathrm{dl})$ reduction, respectively $(\mathrm{p}<0.001)[82]$.

\section{Fibrates versus vitamin $\mathrm{E}$}

In a study by Badiou et al. $36 \mathrm{HIV}$-infected patients with fasting TG of $177 \mathrm{mg} / \mathrm{dl}$ or higher were randomized to receive micronized fenofibrate ( $200 \mathrm{mg} /$ day) or vitamin E ( $500 \mathrm{mg} / \mathrm{day})$ for 3 months and then both drugs combined for an additional 3-month period [100]. The mean baseline TG level was $309 \mathrm{mg} / \mathrm{dl}$. After 3 months, there was a reduction of $40 \%$ (from 3.49 to $2.09 \mathrm{mmol} / \mathrm{l}$ ) in TG and $17 \%$ (5.87 to $4.89 \mathrm{mmol} / \mathrm{l})$ in non-HDL-C and an increase of $15 \%$ (1.00 to $1.16 \mathrm{mmol} / \mathrm{l})$ in HDL-C in the fenofibrate arm and there were no significant changes in the vitamin $\mathrm{E}$ arm. Furthermore, fenofibrate increased LDL particle size and enhanced resistance of LDL to oxidation. These results strongly suggested that in HIVinfected patients with hypertriglyceridemia, initiating treatment with fenofibrate results in improvements in the atherogenic lipid profile of HIV-infected patients.

\section{Fibrates \& statins}

As suggested by ACTG A5087, dual therapy with a statin and a fibrate is generally effective in improving atherogenic lipid profiles. However, when targeting hypertriglyceridemia, the statin-fibrate combination will not necessarily result in additional improvement in TG levels. While there was a robust decrease in TG after 12 weeks on fenofibrate (35\% reduction, $-119 \mathrm{mg} / \mathrm{dl}$ ), there was no additional improvement in TG level after pravastatin was added from week 12 to 48 [86]. This highlights the importance of initiating appropriate treatment targeting the patient's specific presenting lipid abnormality and then modifying treatment based on response to initial treatment in accordance with IDSA guidelines. For patients presenting with TG level between 200 and $500 \mathrm{mg} / \mathrm{dl}$ and elevated LDL-C, initial treatment should consist of a statin alone while in patients with TG $>500 \mathrm{mg} / \mathrm{dl}$, initial treatment should be with fibrates or alternatively, fish oil or niacin. After assessment of response to the initial treatment, combination therapy with fibrate and statin can be considered as needed to reach target lipid levels [65]. In combination therapy, caution must be exercised with gem-fibrozil as it interacts with statin metabolism by inhibiting 
glucuronidation and only lower doses of statins should be used concomitantly with gemfibrozil [101]. Fenofibrate does not interact in this manner with statins and can be coadministered safely without requiring dose modification.

\section{Fish oil}

Fish oil offers another weapon in the armamentarium against hypertriglyceridemia with additional beneficial properties including anti-inflammatory properties and lack of drug interactions with ART agents. The AHA recommends at least two servings of fish per week for healthy adults. For patients with elevated TG, AHA recommends $2-4$ g/day of eicosapentanoic acid (EPA) and docosahexanoic acid (DHA) [102].

In HIV-infected patients, various interventional studies to evaluate fish oil for elevated TG have been conducted. In a randomized, open-label, prospective study by Wohl et al., 52 HIV-infected patients taking ART with elevated TG (mean $=461 \mathrm{mg} / \mathrm{dl}$ ) were randomized to receive dietary and exercise counseling alone or dietary and exercise counseling with EPA + DHA (2.9 g/day). At 4 weeks the 26 patients in the fish oil arm achieved a mean $25 \%$ decrease (from 461 to $306 \mathrm{mg} / \mathrm{dl}$ ) in TG levels [103].

Another double-blind, placebo-controlled trial randomized 122 HIV-infected patients on ART with baseline TG $>2 \mathrm{~g} / \mathrm{l}$ to fish oil (EPA + DHA, $1.8 \mathrm{~g} /$ day) or placebo three-times daily for 8 weeks and showed a mean decrease in TG level of $25.5 \%$ (from 4.4 to $3.4 \mathrm{~g} / \mathrm{l}$ ) for the fish oil arm and no change in the placebo arm (4.7-4.8 g/l) [104].

In the open-label ACTG A5186 study, 100 patients were randomized to receive $3 \mathrm{~g}$ of fish oil supplements twice daily (EPA + DA $4.86 \mathrm{~g} /$ day) or fenofibrate $160 \mathrm{mg} /$ day. The fish oil group was able to reduce TG by $46 \%(283 \mathrm{mg} / \mathrm{dl})$ while the fenofibrate group achieved a $58 \%(367 \mathrm{mg} / \mathrm{dl})$ reduction at 8 weeks [105]. Patients failing to achieve NCEP TG level goal of $<200 \mathrm{mg} / \mathrm{dl}$ were then treated with both medications and achieved a $66 \%$ reduction in TG from baseline by week 18 . However, only $23 \%$ of study patients reached TG goal. In an open-label, randomized, parallel and crossover design study, one group received $1 \mathrm{~g}$ salmon oil administered three times/day. In this study, the group receiving salmon oil did not achieve a significant decrease in TG although there were several study limitations including lack of dietary intervention before the study start, the low dose of EPA + DHA and concomitant lipid-lowering therapy used by more than 50\% of study participants [106].

\section{Niacin}

There are limited published data on the use of niacin to decrease elevated TG in HIVinfected patients. In the open-label ACTG A5148, extended-release niacin was given in escalating doses for up to 44 weeks to 33 HIV-infected patients on ART who had TG levels higher than $200 \mathrm{mg} / \mathrm{dl}$ [107]. Niacin was well tolerated (only four subjects had to discontinue therapy) and $70 \%$ were able to increase the daily dose to the full $2000 \mathrm{mg} / \mathrm{day}$. At 48 weeks, median TG decreased by $38 \%(-1.73 \mathrm{mmol} / \mathrm{l})$. In a similar study by Gerber $e t$ al. 14 HIV-infected patients with elevated TG were given extended-release niacin for 14 weeks and a decrease of 34\% (489-406 mg/dl) in median TG level was observed at week 18 [108]. Niacin can induce insulin resistance which limits its use in pre-diabetic or diabetic patients. In both studies, mild elevations in fasting glucose were commonly observed, although impaired glucose tolerance was reported in one subject in A5148 and in 7 of 11 evaluable subjects (only three developed tolerance during the study) in the study by Gerber et al. 


\section{Switching ART to manage dyslipidemia}

A general strategy that is sometimes considered in patients with significant dyslipidemia while taking ART is changing the ART regimen to a more 'lipid friendly' one [109]. Current guidelines highlight the multifactorial nature of dyslipidemia on HIV-infected patients taking ART and warn that switching ART by itself may not produce the expected improvements in lipid parameters [65]. In patients with pre-existing dyslipidemia prior to starting ART that worsens on ART, it is unlikely that lipids will normalize by switching ART alone without concomitant lipid-lowering medications.

The experience with ART switching in clinical studies involves replacing those agents known to increase lipids significantly with ones with more benign effects on lipids, while maintaining virologic efficacy.

In the ATAZIP study, 248 patients were randomized to switch from ritonavir-boosted, lopinavir to ritonavir-boosted atazanavir or to continue on lopinavir/ritonavir [110]. At week 48 there were significant reductions in TC $(-19 \mathrm{mg} / \mathrm{dl}$ in the atazanavir/ritonavir arm and -4 $\mathrm{mg} / \mathrm{dl}$ in the lopinavir/ritonavir arm, $\mathrm{p}<0.001)$ and TG $(-53 \mathrm{mg} / \mathrm{dl}$ in the atazanavir/ ritonavir and $-4 \mathrm{mg} / \mathrm{dl}$ in the lopinavir/ritonavir arms, $\mathrm{p}<0.001$ ) with no significant differences in LDL-C and HDL-C [110]. In the Switching to Atazanavir (SWAN) study 419 subjects on PI-based ART were randomized to switch to atazanavir or continue their current PI regimen [111]. Only 9\% of those who switched to atazanavir took ritonavir for boosting. Decreases in TC levels $(-15 \%, 212-181 \mathrm{mg} / \mathrm{dl}$, vs $-3 \%, 220-216 \mathrm{mg} / \mathrm{dl})$ and TG levels $(-33 \%, 203-137 \mathrm{mg} / \mathrm{dl}$, vs an increase of $9 \%, 201-216 \mathrm{mg} / \mathrm{dl})$ were observed for those who switched to atazanavir and those who continued on the same PI regimen, respectively. As in the ATAZIP study, no significant changes in HDL-C or LDL-C were observed.

In the Gilead 903 study comparing tenofovir and stavudine on an efavirenz-based regimen, subjects on the stavudine arm had an increase in mean TG of $102 \mathrm{mg} / \mathrm{dl}$ and in mean TC of $59 \mathrm{mg} / \mathrm{dl}$ by year 3 . After switching from stavudine to tenofovir, TG and TC decreased by a mean of 61 and $21 \mathrm{mg} / \mathrm{dl}$, respectively, by year 5 ( $<<0.001$ for both) [112].

An important caveat in switching ART is that it may lead to virologic failure, particularly in patients with underlying ART-resistant virus. For example, in the SWITCHMRK 1 and 2 studies, patients on ritonavir-boosted lopinavir with undetectable viral load at baseline were randomized to switch to raltegravir or remain on lopinavir/ritonavir [113]. There was significant improvement in lipid parameters with changes at 24 weeks in TC of -12.6 versus $1 \%$, in non-HDL-C of -15 versus $2.6 \%$ and in TG of -42.2 versus $6.2 \%$ for those who switched to raltegravir and those who remained on lopinavir/ritonavir, respectively. However, patients switched to raltegravir had a significantly greater proportion of virologic failures than those who remained on lopinavir/ritonavir and the study was stopped early due to lower than expected virologic efficacy.

Another strategy involving ART modification is to 'add' ART agents, like tenofovir, to an existing ART regimen. In patients with detectable viremia, the primary aim is to intensify the ART regimen to achieve virologic suppression. When tenofovir is added as the intensification agent, its relatively benign effect on lipids can result in improvements in lipid parameters. For example, in the Gilead Study 907 study patients on ART who had detectable viral loads between 400 and 10,000 copies/ml were randomized to add tenofovir or placebo [114]. At 24 weeks there was a modest decrease in TC of $17 \mathrm{mg} / \mathrm{dl}$ and in TG of $24 \mathrm{mg} / \mathrm{dl}$. When the placebo group was rolled over to receive tenofovir from weeks 24 to 48 , TC decreased by $12.1 \mathrm{mg} / \mathrm{dl}$ and TG by $22 \mathrm{mg} / \mathrm{dl}$. Similarly, tenofovir could be added safely to stable ART regimens in virologically suppressed patients for the purposes of improving lipid profile as demonstrated in ACTG A5206 [57]. In some cases, switching ART may allow for 
subsequent discontinuation of lipid-lowering medications started after initiation of ART. For example, Martinez et al. reported that in 162 subjects who were taking lipid-lowering therapy and switched to ritonavir-boosted atazanavir from other ART regimens as part of the Bristol Myers Squibb early access program, almost a third were able to subsequently discontinue lipid-lowering medications [115].

Although the data are very limited, adding lipid-lowering therapy may be more beneficial than switching ART. In a study of HIV-infected patients with mixed hyperlipidemia on their initial ART regimen, patients were randomized to switch from a PI to a NNRTI (nevirapine or efavirenz) or to add pravastatin or bezafibrate to their unchanged ART regimen [116]. TG levels decreased by $25,9,41$ and $47 \%$ at 12 months for patients on nevirapine, efavirenz, pravastatin and bezafibrate, respectively. There were statistically significant differences between the nevirapine and efavirenz arms and between the pravastatin and bezafibrate arms ( $\mathrm{p}<0.01$ for both). Furthermore, lipid-lowering therapy with pravastatin or bezafibrate resulted in significantly greater decreases in TC and LDL-C than switching ART to nevirapine or efavirenz.

Overall, switching ART by replacing ART medications should be reserved for patients who have developed significant lipid abnormalities on a specific ART regimen, are unable to attain lipid control with standard lipid-lowering therapy, or cannot tolerate lipid-lowering agents. Special care must be taken to ensure that a switch in ART will not result in loss of virologic control [113].

\section{Conclusion}

HIV infection is associated with increased risk of CHD due primarily to traditional risk factors but also, in part, to chronic inflammatory changes and immune activation caused by HIV infection itself as well as metabolic side effects of ART agents. In fact, uncontrolled HIV infection appears to be a more important contributor to cardiovascular risk than ART, as demonstrated by the increase in CHD events seen in HIV-infected patients undergoing treatment interruption compared with those on continuous ART in the SMART study [30]. Epidemiologic associations between dyslipidemia and CHD risk in HIV-infected persons are supported by data from large cohorts of HIV-infected persons such as D:A:D $[22,67]$. There is no reason to believe that traditional risk reduction strategies will not translate into benefit for those with HIV infection; therefore aggressive management of dyslipidemia, smoking cessation, exercise and weight management are warranted in all HIV-infected patients.

Dyslipidemia in HIV infection presents with distinct lipid patterns associated with uncontrolled HIV disease and with restoration of health after initiation of ART. Individual host demographic and genetic characteristics and metabolic abnormalities caused by specific ART combinations, such as ritonavir-boosted PIs, contribute greatly to the type and degree of dyslipidemia seen in HIV-infected patients taking ART. Effective management of dyslipidemia can be challenging due to the multiple drug-drug interactions between individual ART agents and lipid-lowering therapies. However, several commonly used lipidlowering therapies including many statins, fibrates and fish oil combinations have been evaluated in HIV-infected individuals and have also been demonstrated to be effective in reducing TC, LDL-C and TG levels. Statin-associated pleiotropic improvements in markers of inflammation and endothelial function observed in the general population have not yet been demonstrated in HIV-infected patients but are currently in study. Bile acid resins such as cholestipol and cholestyramine could reduce absorption of ART medications and should be avoided in HIV-infected patients. It is important to target specific dyslipidemia patterns in each patient with the appropriate lipid-lowering therapies in the recommended sequence according to the established guidelines [65]. Careful lipid-lowering therapy selection is 
required to avoid potentially serious drug-drug interactions with the patient's ART. If lipid level goals are not reached with individual lipid-lowering therapies, combinations such as statin-ezetimibe, statin-fibrate and fibrate-fish oil may be indicated. Switching ART to a more lipid neutral regimen may be considered to improve ART-induced dyslipidemia. However, given the risk of virologic failure, replacement of ART should only be performed when lipid control cannot be achieved with lipid-lowering therapies or when lipid-lowering agents cannot be tolerated.

\section{Future perspective}

As HIV has now become a chronic condition that can be effectively managed with potent and tolerable ART regimens, CHD is becoming more prevalent in HIV-infected patients as our population ages. With the increased availability of new ART agents that are less metabolically disruptive and with continued identification of polymorphisms associated with increased risk of CHD and propensity to develop ART-specific lipid abnormalities, it may become possible in the near future to include pharmacogenetic screening as a standard procedure prior to initiation of ART. This will allow HIV clinicians to individualize ART for each patient to minimize the development of significant lipid alterations. In patients with established dyslipidemia, pharmacogenetic screening could help to select the specific lipidlowering therapy that is most likely to result in the largest treatment response for each individual patient.

Finally, as we learn more about the pathophysiology of chronic inflammation and endothelial dysfunction in HIV infection, it may become possible to identify lipid-lowering agents that can also target the inflammatory pathways active in HIV infection in order to further reduce CHD risk.

\section{Bibliography}

Papers of special note have been highlighted as:

- of interest

-" of considerable interest

1. Friis-Moller N, Reiss P, Sabin C, et al. Class of antiretroviral drugs and the risk of myocardial infarction. N Engl J Med. 2007; 356(17):1723-1735. [PubMed: 17460226]

2. Grunfeld C, Pang M, Doerrler W, Shigenaga JK, Jensen P, Feingold KR. Lipids, lipoproteins, triglyceride clearance and cytokines in human immunodeficiency virus infection and the acquired immunodeficiency syndrome. J Clin Endocr Metabo. 1992; 74(5):1045-1052.

3. Klein, DHL.; Quesenberry, C.; Silverberg, M.; Horberg, M.; Sidney, S. Hospitalizations for CHD and $\mathrm{MI}$ among northern California $\mathrm{HIV}^{+}$and $\mathrm{HIV}^{-}$men: changes in practice and Framingham risk scores. Presented at: 13th Conference on Retroviruses and Opportunistic Infections; Denver, CO, USA. 5-8 February 2006;

4. Triant V, Lee H, Hadigan C, Grinspoon S. Increased acute myocardial infarction rates and cardiovascular risk factors among patients with human immunodeficiency virus disease. J Clin Endocr Metab. 2007; 92(7):2506-2512. [PubMed: 17456578]

5. Obel N, Thomsen H, Kronborg G, et al. Ischemic heart disease in HIV-infected and HIV-uninfected individuals: a population-based cohort study. Clin Infect Dis. 2007; 44(12):1625-1631. [PubMed: 17516408]

6. Saves M, Chene G, Ducimetire P, et al. Risk factors for coronary heart disease in patients treated for human immunodeficiency virus infection compared with the general population. Clin Infect Dis. 2003; 37(2):292-298. [PubMed: 12856222]

7-. Hsue P, Hunt P, Schnell A, et al. Role of viral replication, antiretroviral therapy, and immunodeficiency in HIV-associated atherosclerosis. AIDS. 2009; 23(9):1059-1067. Carotid 
intima-media thickness study that demonstrated increased atherosclerosis in HIV-infected patients (including elite controllers without viremia) compared with HIV seronegative persons. [PubMed: 19390417]

8. Tebas P, Henry W, Matining R, et al. Metabolic and immune activation effects of treatment interruption in chronic HIV-1 infection: implications for cardiovascular risk. PLoS ONE. 2008; 3(4):e2021. [PubMed: 18431498]

9. O’Leary DH, Polak JF, Kronmal RA, Manolio TA, Burke GL, Wolfson SK. Carotid-artery intima and media thickness as a risk factor for myocardial infarction and stroke in older adults. Cardiovascular health study collaborative research group. N Engl J Med. 1993; 340(1):14-22.

10. Lorenz M, Markus H, Bots M, Rosvall M, Sitzer M. Prediction of clinical cardiovascular events with carotid intima-media thickness: a systematic review and meta-analysis. Circulation. 2007; 115(4):459-467. [PubMed: 17242284]

11. Grunfeld C, Delaney JAC, Wanke C, et al. Preclinical atherosclerosis due to HIV infection: carotid intima-medial thickness measurements from the FRAM study. AIDS. 2009; 23(14):1841-1849. [PubMed: 19455012]

12. Hulten E, Mitchell J, Scally J, Gibbs B, Villines TC. HIV positivity, protease inhibitor exposure and subclinical atherosclerosis: a systematic review and meta-analysis of observational studies. Heart. 2009; 95(22):1826-1835. [PubMed: 19632982]

13. Lo J, Abbara S, Shturman L, et al. Increased prevalence of subclinical coronary atherosclerosis detected by coronary computed tomography angiography in HIV-infected men. AIDS. 2010; 24(2):243-253. [PubMed: 19996940]

14. Hurley, LLW.; Xu, L.; Silverberg, M., et al. Updated surveillance of cardiovascular event rates among HIV-infected and HIV-uninfected Californians, 1996 to 2008. Presented at: 16th Conference on Retroviruses and Opportunistic Infections; Montreal, Canada. 8-11 February 2009;

15. Lichtenstein, KAC.; Buchacz, K.; Moorman, A.; Wood, K.; Brooks, J. HIV Outpatient Study Group. Analysis of cardiovascular risk factors in the HIV outpatient study cohort. Presented at: 13th Conference on Retroviruses and Opportunistic Infections; Denver, CO, USA. 5-8 February 2006;

16. Wilson PW, D’ Agostino RB, Levy D, Belanger AM, Silbershatz H, Kannel WB. Prediction of coronary heart disease using risk factor categories. Circulation. 1998; 97(18):1837-1847. [PubMed: 9603539]

17. Stamler J, Wentworth D, Neaton JD. Is relationship between serum cholesterol and risk of premature death from coronary heart disease continuous and graded? Findings in 356,222 primary screenees of the multiple risk factor intervention trial (MRFIT). JAMA. 1986; 256(20):2823-2828. [PubMed: 3773199]

18. The Lipid Research Clinics Coronary Primary Prevention Trial results. I. Reduction in incidence of coronary heart disease. JAMA. 1984; 251(3):351-364. [PubMed: 6361299]

19. Gordon DJ, Probstfield JL, Garrison RJ, et al. High-density lipoprotein cholesterol and cardiovascular disease. Four prospective American studies. Circulation. 1989; 79(1):8-15. [PubMed: 2642759]

20. Cullen P. Evidence that triglycerides are an independent coronary heart disease risk factor. American J Cardiol. 2000; 86(9):943-949.

21. Sarwar N, Danesh J, Eiriksdottir G, et al. Triglycerides and the risk of coronary heart disease: 10,158 incident cases among 262,525 participants in 29 western prospective studies. Circulation. 2007; 115(4):450-458. [PubMed: 17190864]

22. Worm, SKA.; El-Sadr, W.; Kirk, O., et al. on behalf of the D:A:D Study Group. Triglycerides and the risk of myocardial infarction in the D:A:D study. Presented at: 17th Conference on Retroviruses and Opportunistic Infections; San Francisco, CA, USA. 16-19 February 2010;

23. Rose H, Hoy J, Woolley I, et al. HIV infection and high density lipoprotein metabolism. Atherosclerosis. 2008; 199(1):79-86. [PubMed: 18054941]

24. Mujawar Z, Rose H, Morrow M, et al. Human immunodeficiency virus impairs reverse cholesterol transport from macrophages. PLoS Biol. 2006; 4(11):E365-E365. [PubMed: 17076584]

25. Riddler SA, Smit E, Cole SR, et al. Impact of HIV infection and HAART on serum lipids in men. JAMA. 2003; 289(22):2978-2982. [PubMed: 12799406] 
26. Riddler S, Li X, Otvos J, et al. Antiretroviral therapy is associated with an atherogenic lipoprotein phenotype among HIV-1-infected men in the multicenter AIDS cohort study. J Acq Imm Defici Synd. 2008; 48(3):281-288.

27-. Riddler SA, Li X, Chu H, et al. Longitudinal changes in serum lipids among HIV-infected men on highly active antiretroviral therapy. HIV Med. 2007; 8(5):280-287. Longitudinal study that describes the lipid changes observed in HIV-infected patients in the MACS cohort before and after starting antiretroviral therapy (ART). [PubMed: 17561873]

28. Hulgan T, Haubrich R, Riddler SA, et al. European mitochondrial DNA haplogroups and metabolic changes during antiretroviral therapy in AIDS Clinical Trials Group Study A5142*. AIDS. 2011; 25(1):37-47. [PubMed: 20871389]

29. Grunfeld C. Dyslipidemia and its treatment in HIV infection. Top HIV Med. 2010; 18(3):112-118. [PubMed: 20921577]

30--. Phillips A, Carr A, Neuhaus J, et al. Interruption of antiretroviral therapy and risk of cardiovascular disease in persons with HIV-1 infection: exploratory analyses from the SMART trial. Antivi Therapy. 2008; 13(2):177-187. Important clinical trial of over $5000 \mathrm{HIV}$-infected patients randomized to CD4-guided intermittent ART or continuous ART. This study showed that there was a significant increased risk of cardiovascular events among patients in the treatment interruption arm compared to those in the continuous therapy arm.

31. Di Angelantonio E, Sarwar N, Perry P, et al. Major lipids, apolipoproteins, and risk of vascular disease. JAMA. 2009; 302(18):1993-2000. [PubMed: 19903920]

32. Kappelle PJWH, Gansevoort RT, Hillege JL, Wolffenbuttel BHR, Dullaart RPF. Apolipoprotein B/ A-I and total cholesterol/high-density lipoprotein cholesterol ratios both predict cardiovascular events in the general population independently of nonlipid risk factors, albuminuria and C-reactive protein. J Int Med. 2011; 269(2):232-242.

33. Briel M, Ferreira-Gonzalez I, You JJ, et al. Association between change in high density lipoprotein cholesterol and cardiovascular disease morbidity and mortality: systematic review and metaregression analysis. BMJ. 2009; 338:B92. [PubMed: 19221140]

34. Kumar PN, Rodriguez-French A, Thompson MA, et al. A prospective, 96-week study of the impact of trizivir, combivir/nelfinavir, and lamivudine/stavudine/nelfinavir on lipids, metabolic parameters and efficacy in antiretroviral-naive patients: effect of sex and ethnicity. HIV Med. 2006; 7(2):85-98. [PubMed: 16420253]

35. Tarr P, Rotger M, Telenti A. Dyslipidemia in HIV-infected individuals: from pharmacogenetics to pharmacogenomics. Pharmacogenomics. 2010; 11(4):587-594. [PubMed: 20350140]

36. Mahungu TW, Nair D, Smith CJ, et al. The relationships of ABCB1 3435C>T and CYP2B6 516G > T with high-density lipoprotein cholesterol in HIV-infected patients receiving Efavirenz. Clin Pharmacol Therapeutics. 2009; 86(2):204-211.

37. Bonnet E, Bernard J, Fauvel J, Massip P, Ruidavets J-B, Perret B. Association of APOC3 polymorphisms with both dyslipidemia and lipoatrophy in HAART-receiving patients. AIDS Res Human Retrovir. 2008; 24(2):169-171. [PubMed: 18240956]

38. Fontas E, van Leth F, Sabin CA, et al. Lipid profiles in HIV-infected patients receiving combination antiretroviral therapy: are different antiretroviral drugs associated with different lipid profiles? J Infect Dis. 2004; 189(6):1056-1074. [PubMed: 14999610]

39. Shafran SD, Mashinter LD, Roberts SE. The effect of low-dose ritonavir monotherapy on fasting serum lipid concentrations. HIV Med. 2005; 6(6):421-425. [PubMed: 16268824]

40. Malan DR, Krantz E, David N, Wirtz V, Hammond J, McGrath D. Efficacy and safety of atazanavir, with or without ritonavir, as part of once-daily highly active antiretroviral therapy regimens in antiretroviral-naive patients. J Acq Imm Defici Synd. 2008; 47(2):161-167.

41. Tomaka F, Lefebvre E, Sekar V, et al. Effects of ritonavir-boosted darunavir vs. ritonavir-boosted atazanavir on lipid and glucose parameters in HIV-negative, healthy volunteers. HIV Med. 2009; 10(5):318-327. [PubMed: 19210693]

42. Overton, TAJ.; Gupta, S.; Ryan, R.; Baugh, B.; De La Rosa, G. METABOLIK: week 48 comparison of metabolic parameters and biomarkers in subjects receiving darunavir/ritonavir or atazanavir/ritonavir. Presented at: 10th International Congress on Drug Therapy in HIV Infection; Glasgow, UK. 7-11 November 2010; 
43. Shikuma C, Yang Y, Glesby M, et al. Metabolic effects of protease inhibitor-sparing antiretroviral regimens given as initial treatment of HIV-1 infection (AIDS Clinical Trials Group Study A5095). J Acquir Immune Defic Syndr. 2007; 44(5):540-550. [PubMed: 17245230]

44. van Leth F, Phanuphak P, Stroes E, et al. Nevirapine and efavirenz elicit different changes in lipid profiles in antiretroviral-therapy-naive patients infected with HIV-1. PLoS Med. 2004; 1(1):e19. [PubMed: 15526045]

45. Katlama C, Haubrich R, Lalezari J, et al. Efficacy and safety of etravirine in treatmentexperienced, HIV-1 patients: pooled 48 week analysis of two randomized, controlled trials. AIDS. 2009; 23(17):2289-2300. [PubMed: 19710593]

46. Hammond E, Nolan D, James I, Metcalf C, Mallal S. Reduction of mitochondrial DNA content and respiratory chain activity occurs in adipocytes within 6-12 months of commencing nucleoside reverse transcriptase inhibitor therapy. AIDS. 2004; 18(5):815-817. [PubMed: 15075519]

47. Jones C, Wilson I, Greenberg A, et al. Insulin resistance in HIV-infected men and women in the nutrition for healthy living cohort. J Acq Imm Defici Synd. 2005; 40(2):202-211.

48-. Worm S, Sabin C, Weber R, et al. Risk of myocardial infarction in patients with HIV infection exposed to specific individual antiretroviral drugs from the 3 major drug classes: the data collection on adverse events of anti-HIV drugs (D:A:D) study. J Infect Dis. 2010; 201(3):318330. Updated analysis from the the Data Collection on Adverse Events of Anti-HIV Drugs (D:A:D) study, an international collaboration of 11 cohorts following more than 33,000 HIVinfected patients in Europe, the USA and Australia. This analysis showed that recent exposure to abacavir or didanosine and cumulative exposure to indinavir or lopinavir-ritonavir were likely associated with increased risk of myocardial infarction. [PubMed: 20039804]

49. Ribaudo H, Benson C, Zheng Y, et al. No risk of myocardial infarction associated with initial antiretroviral treatment containing abacavir: Short and long-term results from ACTG A5001/ ALLRT. Clin Infect Dis. 2011; 52(7):929-940. [PubMed: 21427402]

50. Ding, XA-CE.; Cooper, C.; Miele, P.; Kornegay, P.; Soukup, M.; Marcus, K. No association of myocardial infarction with ABC use: an FDA meta-analysis. Presented at: 18th Conference on Retroviruses and Opportunistic Infections; Boston, MA, USA. February 27-March 2 2011; Poster \#808

51. Satchell C, Cotter A, O'Connor E, et al. Platelet function and HIV: a case-control study. AIDS. 2010; 24(5):649-657. [PubMed: 20177361]

52. Baum, PKG.; Galkina, S.; Stoddart, C.; Weiss, E.; Sullam, P.; McCune, J. Abacavir, a competitive inhibitor of soluble guanylyl cyclase, increases platelet reactivity. Presented at: 17th Conference on Retroviruses and Opportunistic Infections; San Francisco, CA, USA. 16-19 February 2010;

53. de Pablo, COS.; Peris, S.; Apostolova, N.; Esplugues, J.; Alvarez, A. Abacavir induces human leukocyte endothelial cell interactions. Presented at: 17th Conference on Retroviruses and Opportunistic Infections; San Francisco, CA, USA. 16-19 February 2010;

54. Hsue $\mathrm{P}$, Hunt $\mathrm{P}, \mathrm{Wu} \mathrm{Y}$, et al. Association of abacavir and impaired endothelial function in treated and suppressed HIV-infected patients. AIDS. 2009; 23(15):2021-2027. [PubMed: 19542863]

55. Groups SIDADS. Use of nucleoside reverse transcriptase inhibitors and risk of myocardial infarction in HIV-infected patients. AIDS. 2008; 22(14):F17-F24. [PubMed: 18753925]

56. Hill A, Sawyer W, Gazzard B. Effects of first-line use of nucleoside analogues, efavirenz, and ritonavir-boosted protease inhibitors on lipid levels. HIV Clin Trials. 2009; 10(1):1-12. [PubMed: 19362991]

57. Tungsiripat M, Kitch D, Glesby M, et al. A pilot study to determine the impact on dyslipidemia of adding tenofovir to stable background antiretroviral therapy: ACTG 5206. AIDS. 2010; 24(11): 1781-1784. [PubMed: 20495438]

58-. Randell P, Jackson A, Zhong L, Yale K, Moyle G. The effect of tenofovir disoproxil fumarate on whole-body insulin sensitivity, lipids and adipokines in healthy volunteers. Antivir Therapy. 2010; 15(2):227-233. Metabolic study in HIV-seronegative participants showing that tenofovir may have lipid-lowering properties.

59. Mir O, Garrabou G, Lpez S, et al. Short communication metabolic and mitochondrial effects of switching antiretroviral-experienced patients to enfuvirtide, tenofovir and saquinavir/ritonavir. Antivir Therapy. 2006; 11(5):625-630. 
60. Markowitz M, Nguyen B-Y, Gotuzzo E, et al. Rapid and durable antiretroviral effect of the HIV-1 integrase inhibitor raltegravir as part of combination therapy in treatment-naive patients with HIV-1 infection: results of a 48-week controlled study. J Acq Imm Defici Synd. 2007; 46(2):125133.

61. Arribas JR. Secondary effects of treatment with maraviroc and other CCR5 antagonists. Potential impact of the CCR5 blocker. Enferm Infec Microbiol Clin. 2008; 26(Suppl 11):23-27.

62. Samaras K, Richardson R, Carr A. Postprandial lipid effects of low-dose ritonavir vs. raltegravir in HIV-uninfected adults. AIDS. 2010; 24(11):1727-1731. [PubMed: 20588105]

63. Lennox J, Dejesus E, Berger D, et al. Raltegravir versus Efavirenz regimens in treatment-naive HIV-1-infected patients. 96-week efficacy, durability, subgroup, safety, and metabolic analyses. J Acq Imm Defici Synd. 2010; 55(1):39-48.

64-. Rotger M, Bayard C, Taff P, et al. Contribution of genome-wide significant single-nucleotide polymorphisms and antiretroviral therapy to dyslipidemia in HIV-infected individuals: a longitudinal study. Cir Cardiovas Genet. 2009; 2(6):621-628. Study that demonstrates the contribution of single-nucleotide polymorphisms to dyslipidemia in HIV-infected patients in the Swiss HIV cohort.

65--. Dube M, Stein J, Aberg J, et al. Guidelines for the evaluation and management of dyslipidemia in human immunodeficiency virus (HIV)-infected adults receiving antiretroviral therapy: recommendations of the HIV Medical Association of the Infectious Disease Society of America and the Adult AIDS Clinical Trials Group. Clin Infect Dis. 2003; 37(5):613-627. Infectious Disease Society of America/AIDS Clinical Trial Group guidelines for the management of dyslipidemia in HIV-infected patients. Treatment is also recommended for hypertriglyceridemia, an important difference with the European (EACS) guidelines. [PubMed: 12942391]

66. Law MG, Friis-Mller N, El-Sadr WM, et al. The use of the Framingham equation to predict myocardial infarctions in HIV-infected patients: comparison with observed events in the D:A:D study. HIV Med. 2006; 7(4):218-230. [PubMed: 16630034]

67. Friis-Moller N, Thibaut R, Reiss P, et al. Predicting the risk of cardiovascular disease in HIVinfected patients: the data collection on adverse effects of anti-HIV drugs study. Euro J Cardiovas Prevent Rehabili. 2010; 17(5):491-501.

68. Lundgren JD, Battegay M, Behrens G, et al. European AIDS clinical society (EACS) guidelines on the prevention and management of metabolic diseases in HIV. HIV Med. 2008; 9(2):72-81. [PubMed: 18257770]

69-. Fichtenbaum C, Gerber J, Rosenkranz S, et al. Pharmacokinetic interactions between protease inhibitors and statins in HIV seronegative volunteers: ACTG study A5047. AIDS. 2002; 16(4): 569-577. Important pharmacokinetic study showing the significant interaction between simvastatin and protease inhibitors, which result in a 32-fold increase in simvastatin area under the curve. [PubMed: 11873000]

70. Aboulafia DM, Johnston R. Simvastatin-induced rhabdomyolysis in an HIV-infected patient with coronary artery disease. AIDS Pat Care STDs. 2004; 14(1):13-18.

71. Aberg J, Rosenkranz S, Fichtenbaum C, et al. Pharmacokinetic interaction between nelfinavir and pravastatin in HIV-seronegative volunteers: ACTG study A5108. AIDS. 2006; 20(5):725-729. [PubMed: 16514303]

72. Aquilante, CKJ.; Anderson, P.; Christians, U., et al. Influence of SLCO1B1 polymorphisms on pharmacokinetic (PK) variability in the drug-drug interaction between darunavir/ritonavir (DRV/ r) and pravastatin (PRA). Presented at: 50th Interscience Conference on Antimicrobials and Chemotherapy; Boston, MA, USA. 12-15 September 2010;

73. Prezista ${ }^{\circledR}$ (darunavir), package insert. Tibotec Inc; Beerse, Belgium:

74. Livalo ${ }^{\circledR}$ (pitavastatin) package insert. Kowa Pharmaceuticals America Inc; AL, USA:

75. Kiser J, Gerber J, Predhomme J, Wolfe P, Flynn D, Hoody D. Drug/Drug interaction between lopinavir/ritonavir and rosuvastatin in healthy volunteers. J Acq Imm Defici Synd. 2008; 47(5): 570-578.

76. Busti A, Bain A, Hall R, et al. Effects of atazanavir/ritonavir or fosamprenavir/ritonavir on the pharmacokinetics of rosuvastatin. J Cardiovas Pharma. 2008; 51(6):605-610. 
77. Gerber J, Rosenkranz S, Fichtenbaum C, et al. Effect of efavirenz on the pharmacokinetics of simvastatin, atorvastatin, and pravastatin: results of AIDS clinical trials group 5108 study. J Acq Imm Defici Synd. 2005; 39(3):307-312.

78. Grennan T, Walmsley S. Etravirine for HIV-I: addressing the limitations of the nonnucleoside reverse transcriptase inhibitor class. J Int Assoc Physi AIDS Care. 2009; 8(6):354-363.

79. van Luin M, Colbers A, van Ewijk-Beneken Kolmer EWJ, et al. Drug-drug interactions between raltegravir and pravastatin in healthy volunteers. J Acq Imm Defici Synd. 2010; 55(1):82-86.

80. Kiser J. Pharmacologic characteristics of investigational and recently approved agents for the treatment of HIV. Curr Opi HIV AIDS. 2008; 3(3):330-341.

81. Silverberg M, Leyden W, Hurley L, et al. Response to newly prescribed lipid-lowering therapy in patients with and without HIV infection. Ann Int Med. 2009; 150(5):301-313. [PubMed: 19258558]

82. Aberg J, Zackin R, Brobst S, et al. A randomized trial of the efficacy and safety of fenofibrate versus pravastatin in HIV-infected subjects with lipid abnormalities: AIDS clinical trials group study 5087. AIDS Res Human Retrovir. 2005; 21(9):757-767. [PubMed: 16218799]

83. Wohl D, Waters D, Simpson R, et al. Ezetimibe alone reduces low-density lipoprotein cholesterol in HIV-infected patients receiving combination antiretroviral therapy. Clin Infect Dis. 2008; 47(8): 1105-1108. [PubMed: 18781882]

84. Moyle GJ, Lloyd M, Reynolds B, Baldwin C, Mandalia S, Gazzard BG. Dietary advice with or without pravastatin for the management of hypercholesterolaemia associated with protease inhibitor therapy. AIDS. 2001; 15(12):1503-1508. [PubMed: 11504982]

85. Calza L, Manfredi R, Chiodo F. Use of fibrates in the management of hyperlipidemia in HIVinfected patients receiving HAART. Infection. 2003; 30(1):26-31. [PubMed: 11876511]

86-. Fichtenbaum C, Yeh T-M, Evans S, Aberg J. Treatment with pravastatin and fenofibrate improves atherogenic lipid profiles but not inflammatory markers in ACTG 5087. J Clin Lipidol. 2010; 4(4):279-287. Randomized open-label trial of pravastatin versus fenofibrate in HIV-infected patients with dsylipidemia. This study showed that despite improvements in lipid parameters, there were no significant changes in inflammatory markers such as C-reactive protein. [PubMed: 20824151]

87-. Aslangul E, Assoumou L, Bittar R, et al. Rosuvastatin versus pravastatin in dyslipidemic HIV-1infected patients receiving protease inhibitors: a randomized trial. AIDS. 2010; 24(1):77-83. Head-to-head randomized controlled trial comparing rosuvastatin to pravastatin in HIV-infected patients taking protease inhibitors with dyslipidemia. This study showed that rosuvastatin was superior to pravastatin in LDL-C and triglyceride reduction at 45 days in this patient population. [PubMed: 19838098]

88. Calza L, Manfredi R, Colangeli V, Pocaterra D, Pavoni M, Chiodo F. Rosuvastatin, pravastatin, and atorvastatin for the treatment of hypercholesterolaemia in HIV-infected patients receiving protease inhibitors. Cur HIV Res. 2008; 6(6):572-578.

89. Ridker P, Danielson E, Fonseca FAH, et al. Rosuvastatin to prevent vascular events in men and women with elevated C-reactive protein. N Engl J Med. 2008; 359(21):2195-2207. [PubMed: 18997196]

90. Kastelein JJP, Akdim F, Stroes ESG, et al. Simvastatin with or without ezetimibe in familial hypercholesterolemia. N Engl J Med. 2008; 358(14):1431-1443. [PubMed: 18376000]

91. Negredo E, Molt J, Puig J, et al. Ezetimibe, a promising lipid-lowering agent for the treatment of dyslipidaemia in HIV-infected patients with poor response to statins. AIDS. 2006; 20(17):21592164. [PubMed: 17086055]

92. Bennett MT, Johns KW, Bondy GP. Ezetimibe is effective when added to maximally tolerated lipid lowering therapy in patients with HIV. Lipids Health Dis. 2007; 6:15. [PubMed: 17565701]

93-. Chow D, Chen H, Glesby M, et al. Short-term ezetimibe is well tolerated and effective in combination with statin therapy to treat elevated LDL cholesterol in HIV-infected patients. AIDS. 2009; 23(16):2133-2141. Randomized, placebo-controlled trial of HIV-infected patients with dyslipidemia on ART and stable statin therapy. This study demonstrated that ezetimibe led to significant additional reduction in lipids in this patient population. [PubMed: 19770624] 
94. Miller J, Brown D, Amin J, et al. A randomized, double-blind study of gemfibrozil for the treatment of protease inhibitor-associated hypertriglyceridaemia. AIDS. 2002; 16(16):2195-2200. [PubMed: 12409741]

95. Aberg JA. Lipid management in patients who have HIV and are receiving HIV therapy. Endocrinol Metab Clin North Am. 2009; 38(1):207-222. [PubMed: 19217520]

96. Thomas JC, Lopes-Virella MF, Del Bene VE, et al. Use of fenofibrate in the management of protease inhibitor-associated lipid abnormalities. Pharma. 2000; 20(6):727-734.

97. de Luis DA, Bachiller P, Aller R. Fenofibrate in hyperlipidaemia secondary to HIV protease inhibitors. Fenofibrate and HIV protease inhibitor. Nutrition. 2001; 17(5):414-415. [PubMed: 11377136]

98. Caramelli B, de Bernoche CY, Sartori AM, et al. Hyperlipidemia related to the use of HIVprotease inhibitors: natural history and results of treatment with fenofibrate. Braz J Infect Dis. 2001; 5(6):332-338. [PubMed: 11980596]

99. Palacios R, Santos J, Gonzlez M, et al. Efficacy and safety of fenofibrate for the treatment of hypertriglyceridemia associated with antiretroviral therapy. J Acq Imm Defici Synd. 2003; 31(2): 251-253.

100. Badiou S, De Boever C, Dupuy A-M, Baillat V, Cristol J-P, Reynes J. Fenofibrate improves the atherogenic lipid profile and enhances LDL resistance to oxidation in HIV-positive adults. Atherosclerosis. 2004; 172(2):273-279. [PubMed: 15019537]

101. Jacobson T. Myopathy with statin-fibrate combination therapy: clinical considerations. Nat Rev Endocrinol. 2009; 5(9):507-518. [PubMed: 19636324]

102. Kris-Etherton PM, Harris WS, Appel LJ. Omega-3 fatty acids and cardiovascular disease: new recommendations from the American Heart Association. Arterioscler Thromb Vasc Biol. 2003; 23(2):151-152. [PubMed: 12588750]

103. Wohl D, Tien H-C, Busby M, et al. Randomized study of the safety and efficacy of fish oil (omega-3 fatty acid) supplementation with dietary and exercise counseling for the treatment of antiretroviral therapy-associated hypertriglyceridemia. Clin Infect Dis. 2005; 41(10):1498-1504. [PubMed: 16231263]

104. De Truchis P, Kirstetter M, Perier A, et al. Reduction in triglyceride level with n-3 polyunsaturated fatty acids in HIV-infected patients taking potent antiretroviral therapy: a randomized prospective study. J Acq Imm Defici Synd. 2007; 44(3):278-285.

105. Gerber J, Kitch D, Fichtenbaum C, et al. Fish oil and fenofibrate for the treatment of hypertriglyceridemia in HIV-infected subjects on antiretroviral therapy: results of ACTG A5186. J Acq Imm Defici Synd. 2008; 47(4):459-466.

106. Baril J-G, Kovacs C, Trottier S, et al. Effectiveness and tolerability of oral administration of lowdose salmon oil to HIV patients with HAART-associated dyslipidemia. HIV Clin Trial. 2007; 8(6):400-411.

107. Dube M, Wu J, Aberg J, et al. Safety and efficacy of extended-release niacin for the treatment of dyslipidaemia in patients with HIV infection: AIDS Clinical Trials Group Study A5148. Antivi Therapy. 2006; 11(8):1081-1089.

108. Gerber M, Mondy K, Yarasheski K, et al. Niacin in HIV-infected individuals with hyperlipidemia receiving potent antiretroviral therapy. Clin Infect Dis. 2004; 39(3):419-425. [PubMed: 15307011]

109. Barragan P, Fisac C, Podzamczer D. Switching strategies to improve lipid profile and morphologic changes. AIDS Rev. 2006; 8(4):191-203. [PubMed: 17219734]

110. Mallolas J, Podzamczer D, Milinkovic A, et al. Efficacy and safety of switching from boosted lopinavir to boosted atazanavir in patients with virological suppression receiving a LPV/rcontaining HAART: the ATAZIP study. J Acq Imm Defici Synd. 2009; 51(1):29-36.

111. Gatell J, Salmon-Ceron D, Lazzarin A, et al. Efficacy and safety of atazanavir-based highly active antiretroviral therapy in patients with virologic suppression switched from a stable, boosted or unboosted protease inhibitor treatment regimen: the SWAN Study (AI424-097) 48-week results. Clin Infect Dis. 2007; 44(11):1484-1492. [PubMed: 17479947] 
112. Madruga JRV, Cassetti I, Suleiman JM, et al. The safety and efficacy of switching stavudine to tenofovir df in combination with lamivudine and efavirenz in HIV-1-infected patients: three-year follow-up after switching therapy. HIV Clin Trials. 2007; 8(6):381-390. [PubMed: 18042503]

113-. Eron J, Young B, Cooper D, et al. Switch to a raltegravir-based regimen versus continuation of a lopinavir-ritonavir-based regimen in stable HIV-infected patients with suppressed viraemia (SWITCHMRK 1 and 2): two multicentre, double-blind, randomised controlled trials. Lancet. 2010; 375(9712):396-407. Well-conducted randomized study that showed that although ART switch in virologically controlled HIV-infected patients on stable ART can result in lipid improvements, there may be unexpected virologic failure. [PubMed: 20074791]

114. Squires K, Pozniak A, Pierone G, et al. Tenofovir disoproxil fumarate in nucleoside-resistant HIV-1 infection: a randomized trial. Ann Inter Med. 2003; 139(5):313-320.

115. Martinez, EAC.; Antela, A.; Rivero, A., et al. Effects of switching to ritonavir-boosted atazanavir on HIV-infected patients receiving antiretroviral therapy with hyperlipidemia. Presented at: 12th Conference on Retroviruses and Opportunistic Infections; Boston, MA, USA. 22-25 February 2005;

116. Calza L, Manfredi R, Colangeli V, et al. Substitution of nevirapine or efavirenz for protease inhibitor versus lipid-lowering therapy for the management of dyslipidaemia. AIDS. 2005; 19(10):1051-1058. [PubMed: 15958836]

117. Grennan T, Walmsley S. Etravirine for HIV-I: addressing the limitations of the nonnucleoside reverse transcriptase inhibitor class. J Int Ass Phys AIDS Care. 2009; 8(6):354-363.

\section{Website}

201. National Cholesterol Education Program. [Accessed 29 November 2010] Third report on the expert panel on detection, evaluation and treatment of high blood cholesterol in adults (Adult Treatment Panel III). 2002 (Update 2004). www.nhlbi.nih.gov/guidelines/cholesterol/atp3full.pdf 


\section{Executive summary}

Risk of coronary heart disease is increased in HIV-infected individuals compared with the general population

- Traditional risk factors are the main contributors of increased risk of coronary heart disease (CHD).

- Chronic inflammation due to HIV and specific antiretroviral therapy (ART) agents are important contributors to excess CHD risk.

- Myocardial infarction rates in HIV-infected individuals are elevated but decreasing as use of lipid-lowering medications has increased.

\section{Dyslipidemia in HIV-infected patients has distinct patterns}

- In untreated HIV infection, HDL-C, total cholesterol and LDL-C decrease while triglyceride (TG) increases.

- After initiation of ART, total cholesterol and LDL-C increase due to a 'return to health' but HDL-C remains low.

\section{ART effects on lipids}

- Protease inhibitors (PIs) generally increase LDL-C and TG.

- Compared to other PIs, atazanavir and darunavir are associated with more modest lipid increases.

- Non-nucleoside reverse transcriptase inhibitors (NNRTIs) increase lipids less than PIs. Nevirapine and efavirenz also increase HDL-C.

- Stavudine increases lipids most significantly of all NNRTIs.

- Preliminary pilot data suggests that tenofovir has independent lipid-lowering effects.

- Enfuvirtide, maraviroc and raltegravir appear to have no significant effects on lipids.

\section{Lipid management guidelines}

- Infectious Diseases Society of America/AIDS Clinical Trial Group guidelines are based on National Cholesterol Education Program Adult Treatment Panel (NCEP ATP) III guidelines.

- Framingham Risk Score correlates with but may underestimate CHD risk in HIV-infected patients.

- European AIDS Clinical Society guidelines do not recommend treating elevated TG.

- Infectious Diseases Society of America guidelines recommend that for elevated non-HDL-C with TG $200-500 \mathrm{mg} / \mathrm{dl}$, a statin is first-line therapy while for those with $\mathrm{TG}>500 \mathrm{mg} / \mathrm{dl}$ fibrate, fish oil or niacin are first-line therapy.

\section{Lipid-lowering medications \& ART agents have important interactions}

- PIs, NNRTIs and some statins are metabolized by CYP3A4.

- Simvastatin and lovastatin should be avoided with PIs due to risk of serious toxicities. Low dose atorvastatin can be given with PIs. 
- Pravastatin can be given with PIs but may be less effective. However, pravastatin levels can increase fivefold with darunavir.

- Pitavastatin can be given with ritonavir-boosted atazanavir (no data with other PIs).

- Rosuvastatin concentration increases with lopinavir/ritonavir or fosamprenavir/ ritonavir but not with atazanavir/ritonavir.

- Efavirenz decreases concentrations of simvastatin, atorvastatin and pravastatin.

- Raltegravir does not interact with statins.

- Maraviroc is a CYP3A inducer and may interact with statins.

\section{Lipid-lowering strategies in HIV infection are safe \& effective}

- Epidemiologic associations between dyslipidemia and CHD risk in HIVinfected persons are supported by data from large cohorts of HIV-infected persons.

- Rosuvastatin may be superior to pravastatin and atorvastatin in reducing lipids in patients on PI-based ART.

- Ezetimibe with pravastatin improves total cholesterol and LDL-C.

- Bile acid sequestrants should be avoided as they can decrease ART absorption.

- Fenofibrate can be given safely with ART and significantly reduces TG.

- Pravastatin with fenofibrate reduces TG and LDL-C moderately and increase HDL-C slightly.

- Fish oil is a safe and effective alternative to reduce TG in HIV-infected patients on ART.

- Niacin reduces TG by 34-38\% but can produce impaired glucose tolerance.

- Caution should be taken when considering switching ART to improve lipids in view of the small but real risk of virologic failure especially among patients who may have archived antiretroviral resistance. 
Table 1

Interactions between lipid-lowering drugs, protease inhibitors and non-nucleoside reverse transcriptase inhibitors.

\begin{tabular}{|c|c|c|c|}
\hline \multirow[t]{2}{*}{ Statins } & \multicolumn{2}{|c|}{ ART drug class } & \multirow[t]{2}{*}{ Ref. } \\
\hline & $P I$ & NNRTI & \\
\hline Atorvastatin & $\begin{array}{l}\text { Atorvastatin AUC } \uparrow \uparrow \\
\text { Use lowest starting atorvastatin dose }\end{array}$ & $\begin{array}{l}\text { Atorvastatin AUC } \downarrow \downarrow \text { with efavirenz and etravirine } \\
\text { No data for nevirapine } \\
\text { May need higher atorvastatin starting dose with } \\
\text { efavirenz and etravirine }\end{array}$ & {$[69,77,117]$} \\
\hline Fluvastatin & Use not recommended with nelfinavir & $\begin{array}{l}\text { Fluvastatin AUC } \uparrow \text { with etravirine } \\
\text { May need higher fluvastatin starting dose with } \\
\text { etravirine }\end{array}$ & [78] \\
\hline Lovastatin & Contraindicated (lovastatin AUC $\uparrow \uparrow \uparrow$ ) & $\begin{array}{l}\text { Lovastatin AUC } \downarrow \downarrow \text { with efavirenz } \\
\text { May need higher lovastatin starting dose }\end{array}$ & [69] \\
\hline Pitavastatin & $\begin{array}{l}\leftrightarrow \text { with atazanavir } \\
\text { No data on other PIs }\end{array}$ & Unknown & [74] \\
\hline Pravastatin & $\begin{array}{l}\text { AUC } \downarrow \text { of pravastatin except for darunavir, } \\
\text { which may } \uparrow \uparrow \text { pravastatin } \\
\text { AUC fivefold }\end{array}$ & $\begin{array}{l}\text { Pravastatin AUC } \downarrow \downarrow \text { with efavirenz but } \leftrightarrow \text { with } \\
\text { etravirine } \\
\text { May need higher pravastatin starting dose }\end{array}$ & {$[71,72,117]$} \\
\hline Rosuvastatin & $\begin{array}{l}\text { Rosuvastatin AUC } \uparrow \uparrow \text { with lopinavir/ritonavir } \\
\text { and fosamprenavir/ritonavir } \\
\text { May need lower rosuvastatin starting dose } \\
\text { with lopinavir/ritonavir or fosamprenavir/ } \\
\text { ritonavir } \\
\text { Superior to pravastatin and atorvastatin in HIV } \\
\text { patients }\end{array}$ & $\begin{array}{l}\text { Allowed AUC } \leftrightarrow \\
\text { No reported interactions }\end{array}$ & {$[75,76,87,88]$} \\
\hline Simvastatin & Contraindicated (simvastatin AUC $\uparrow \uparrow \uparrow$ ) & $\begin{array}{l}\text { Simvastatin AUC } \downarrow \downarrow \text { with efavirenz and } \downarrow \text { with } \\
\text { etravirine } \\
\text { No data for nevirapine } \\
\text { May need higher simvastatin starting dose }\end{array}$ & {$[69,70,78]$} \\
\hline Ezetimibe & No dose modification & No dose modification & \\
\hline Fibrates & No dose modification & No dose modification & \\
\hline Bile acid sequestrants & $\begin{array}{l}\text { May interference with absorption of PIs } \\
\text { Do not use }\end{array}$ & $\begin{array}{l}\text { May interfere with absorption of NNRTIs } \\
\text { Do not use }\end{array}$ & \\
\hline Niacin & No dose modification & No dose modification & \\
\hline Fish oil & No dose modification & No dose modification & \\
\hline
\end{tabular}

$\uparrow:$ Some increase; $\uparrow \uparrow:$ Moderate increase; $\uparrow \uparrow \uparrow:$ Large increase; $\downarrow$ : Some decrease; $\leftrightarrow:$ Unchanged; ART: Antiretroviral therapy; AUC: Area under the curve; NNRTI: Non-nucleoside reverse transcriptase inhibitor; PI: Protease inhibitor. 